\title{
PENGARUH RESISTANCE BAND EXERCISE DAN POWER TUNGKAI TERHADAP HASIL TENDANGAN LAMBUNG DALAM PERMAINAN SEPAKBOLA PADA ATLET SSB SRIWIJAYA ASAH SOCCER (SAS) U-15 PALEMBANG
}

\author{
M. Al-Ghani \\ Universitas Islam Kalimantan Muhammad Arsyad Al Banjary \\ Email: alghani@uniska-bjm.ac.id
}

\begin{abstract}
ABSTRAK
Tujuan dari penelitian ini adalah untuk mengetahui dan mendeskripsikan: (1) Perbedaan metode latihan standing leg extension dan leg back press terhadap peningkatan hasil tendangan lambung sepak bola atlet SSB Sriwijaya Asah Soccer U-15 Palembang.(2) Pengaruh perbedaan antara atlet yang memiliki power tungkai tinggi dan atelat yang memiliki power tungkai rendah terhadap hasil tendangan lambung sepak bola pada atlet SSB Sriwijaya Asah Soccer Palembang.(3)Interaksi antara metode latihan resistance band dan power tungkai terhadap peningkatan hasil tendangan lambung sepak bola pada atlet SSB Sriwijaya Asah Soccer Palembang. Hasil penelitian ini: (1)Metode latihan standing leg extension memilki hasil rata-rata sebesar 36,852, sedangkan metode latihan leg back press memiliki hasil rata-rata sebesar 33,711 terhadap peningkatan hasil tendangan lambung sepak bola.(2) Atlet yang memilki power tungkai tinggi memilki hasil rata-rata sebesar 37,716, sedangkan atlit yang memiliki power rendah memilki hasil rata-rata sebesar 32,848 dalam peningkatan hasil tendangan lambung sepak bola. (3)Terdapat interaksi antara metode latihan standing leg extension dan leg back press dan power tungkai terhadap peningkatan hasil tendangan lambung sepak bola Kelompok dengan menggunakan metode latihan standing leg extension mengalami rata-rata peningkatan hasil tendangan lambung sebesar 39,797 untuk atlet yang memilki power tinggi dan 33,907 untuk atlet yang memiliki power rendah. Kelompok perlakuan dengan menggunakan metode latihan leg back press mengalami rata-rata peningkatan hasil tendangan lambung sebesar 35,634 untuk atlet yang memiliki power tinggi dan 31,789 untuk atlet yang memilki power tungkai rendah.
\end{abstract}

Kata Kunci: Latihan Resistance Band, Power Tungkai, Hasil Tendangan Lambung

\begin{abstract}
The purpose of this research is to find out and describe:(1)influence of difference exercise standing leg extension and leg back press against improvement instep kick in football of SSB Sriwijaya Asah Soccer Palembang.(2)the influence of and diffrences between athletes who had the high leg power and has low leg power skills against instep kick in football athelete of SSB Sriwijaya Asah Soccer Palembang.(3)the interaction between the method of exercise resistance band and leg power against an increase in instep kick football results on athelete SSB Sriwijaya Asah Soccer PalembangThe results of this study: (1) the method of practice standing leg extension had an average yield of 36,852, while the leg back press exercise method have an average yield of 33,711 against increased instep kick football results. (2) atheltes who have high limb power had average yield of 37,716, while athlete who have low power has an average yield of 32,848 in increased gastric kick football results. (3) there is interaction between the methods of practice standing leg extension and leg press back and leg power back toward an increase in instep kick football results. Group using exercise standing leg extension experienced an average increase in gastrick kick results of 39,797 for athlete who have haigh power and 33,907 for athletes that have power low. Group treatment by using method of exercise leg back press experienced an average increase in gastric kick results of 35,634 for athletes who have high power and 31,789 for athletes who have the power limbs
\end{abstract}

Keywords: Resistance band, Leg Power, Instep Kick

Dipublikasikan Oleh :

UPT Publikasi dan Pengelolaan Jurnal

Universitas Islam Kalimantan Muhammad Arsyad Al-Banjari Banjarmasin 


\section{PENDAHULUAN}

Menurut Chandra dan Sanoesi (2010:2) sepakbola merupakan permainan yang dilakukan dua regu/tim. Setiap pemain terdiri dari 11 pemain. Permainan sepakbola membutuhkan kerjasama timyang kompak. Di samping itu, variasi dan kombinasi teknik-teknik dasar juga diperlukan dalam permainan ini. Lanjut menurut Chandara dan Sanoesi (2010:2) teknik-teknik dasar permainan sepakbola sangat penting untuk diketahui, sebagailangkah menujupermainan yang baik dan menarik untuk ditonton. Teknik-teknik dasar itu adalah menendang bola, menghentikan bola, menggiring bola, menyundul bola.

Dewasa ini Sepak bola mengalami perkembangan yang sangat pesat. Hal ini bisa kita perhatikan pada peralatan, sarana dan prasarana olahraga yang dipakai, contohnya digunakaknnya bola pintar, kamera pengawas dan yang lebih menakjubkan lagi adalah stadion, yang mana stadion tersebut bisa membuka sendiri saat ada hujan ataupun panas. Prestasi yang tinggi bukan hanya dipengaruhi oleh sarana dan prasarana, tetapi juga aspek biologis psikologis, dan lingkungan.

Menurut Ari Setiawan menyatakan bahwa salah satu faktor yang sangat menentukan prestasi olahraga nasional adalah konsep latihan (training) itu sendiri. Sepakbola Nasional (apalagi regional/local), yang disebut latihan Sepakbola sering hanya "bermain bola". Latihan Sepakbola hanya dianggap sekedar berkumpul-kumpul saja, tending bola sebentar langsung "bermain Sepakbola" sebelas lawan sebelas dilapangan. Bisa dibayangkan, dalam satu kali "bermain Sepakbola" berapa kali rata-rata seseorang pemain menendang bola hanya 10-20 kali saja, dan dengan semakin berbakat seseorang, dia akan semakin menonjol, tetapi bagi yang "kurang berbakat" maka ia akan semakin tertinggal. Karena dilatih untuk "bermain sepak bola" maka teknik Sepakbola pun tidak berkembang.

Menurut Sucipto, dkk (2000:8) gerakan yang paling dominan dalam permainan Sepakbola adalah menendang. Dengan demikian gerakan menendang saja anak-anak sudah dapat bermain Sepakbola. Dilihat dari rumpun gerak dan ketrampilan dasar, terdapat tiga dasar ketrampilan diantaranya adalah Lokomotor, Non lokomotor dan Manipulatif. Pemain yang memiliki teknik menendang dengan baik, akan mampu bermain secara efisien. Tujuan menendang bola adalah untuk mengumpan (passing), mnembak kegawang (shooting at the goal), dan menyapu (menjauhkan bola dari gawang sendiri) dan menyapu untuk menggagalkan serangan lawan (sweeping).

Menurut perkenaan kaki, tendangan dalam sepakbola dapat dibedakan menjadi beberapa macam : 1) Dengan kaki bagian dalam, 2) Dengan kura-kura kaki bagian dalam, 3) Dengan kura-kura kaki penuh, 4) Dengan ujung jari, 5) Dengan kura-kura kaki bagian luar, 6) Dengan tumit (Sukatamsi, 1984 : 47).

Teknik menendang bola dilihat dari perkenaan bagian kaki ke bola, menurut Remmy Muchtar (1992:29) ada empat cara dalam menendang bola, yakni : dengan kaki bagian dalam (inside-foot), dengan punggung kaki (instep-foot) dengan punggung kaki bagian dalam (inside-instep). Ketika diberi operan oleh kawannya, baik operan itu datar, lambung, keras maupun pelan, pemain harus mampu mengontrol bola dan menahan bola agar tidak hilang di ambil lawan dengan menggunakan kaki, baik kaki bagian dalam, punggung kaki, punggung kaki bagian luar, sol sepatu, paha, dada maupun kepala tergantung dengan arah datangnya bola.

Menurut tinggi rendahnya bola, tendangan dalam sepakbola ada beberapa macam yaitu : 1) Tendangan bola rendah, 2) Tendangan bola melambung sedang yaitu lambungan setinggi lutut dan kepala, 3) Tendangan bola melambung tinggi yaitu paling rendah setinggi kepala (Sukatamsi, 1984 : 48).

Tendangan lambung adalah memindahkan bola dari satu tempat ke tempat lain dengan menggunakan punggung kaki bagian dalam melalui passing melambung sejauh-jauhnya. Tendangan lambung menurut Sucipto (2000:21) pada umumnya menendang dengan punggung kaki bagian dalam digunakan untuk mengumpan jarak jauh (long pass).

Analisis gerak menendang dengan punggung kaki bagian dalam, pengukuran dimulai dari titik tending sampai bola jatuh menyentuh permukaan lapangan. Bola menyusur tanah dianggap tidak sah sehingga tendangan bola harus lambung atau melayang dengan memperhatikan sudut elevasi 45o. Seperti dikemukakan Soedarminto dalam Heru Sulistianta, S.Pd, M.Or (2013:31), ada suatu pola hubungan antara sudut elevasi, jarak vertical, dan jarak horizontal dari lintasan geraknya

Ditinjau dari fungsinya, tendangan lambung (instep kick) memiliki kontribusi besar yaitu, untuk memberikan umpan jarak jauh secara parabola (melambung) dan umpan ke daerah gawang lawan. Umpanumpan yang tepat dan akurat akan memudahkan teman seregu untuk menerima ataupun mencetak gol ke gawang lawan. Selain itu, tendangan lambung memiliki efektivitas yang cukup baik, bila bola dalam keadaan melambung di atas sangat kecil kemungkinan untuk digagalkan oleh lawan. Pentingya peranan tendangan lambung, maka dari itu harus dilatih dan di kembangkan secara sistematis dan berkelanjutan. Adapun prinsip tekhnik menendang

Dipublikasikan Oleh :

UPT Publikasi dan Pengelolaan Jurnal

Universitas Islam Kalimantan Muhammad Arsyad Al-Banjari Banjarmasin 
lambung yaitu: kaki tumpu, kaki untuk menendang (kanan atau kiri), gerakan ayunan kakipandangan mata, bagian bola yang ditendang, sikap badan setelah menendang serta otot tungkai yang kuat.

Saat ini perkembangan permainan sepakbola sangat pesat sekali, hal ini ditandai dengan banyaknya sekolah-sekolah sepakbola (SSB) yang didirikan (Rofa, 2008). Sekolah Sepakbola Sriwijaya Asah Soccer yang berasal dari kota Palembang adalah suatu wadah untuk menyalurkan hobi atau bakat dalam bermain sepakbola untuk pemain usia dini sampai remaja. Salah satu jenjang yang dimiliki SSB ini adalah jenjang praremaja yakni usia 13-15 tahun.

Sejak berdirinya SSB ini, mereka selalu mengikuti kompetisi yang digelar di Kota Palembang. Dalam kurun waktu 4 tahun terakhir, SSB Sriwijaya Asah Soccer U 15 hanya mendapatkan peringkat ke3 dalam suatu turnamen yang di gelar di Kota Palembang. SSB Sriwijaya Asah Soccer khususnya U-15 memang minim secara prestasi, akan tetapi ada beberapa atlet yang sering di panggil untuk memperkuat tim HAORNAS maupun SURATIN kota Palembang.

Menurut informasi yang diberikan oleh pelatih (Syahriful Alamsyah Sitompul) SSB Sriwijaya Asah Soccer bawasanya masih banyak atlit usia di bawah 15 tahun kurang mampu menguasai keterampilan tekhnik menendang bola lambung dengan baik. Hal ini dapat dilihat dari pemain SSB Sriwijaya Asah Soccer Palembang pada saat melakukan latihan maupun dalam pertandingan. Kualitas tendangannya kurang baik, sehingga saat melakukan tendangan lambung bola sering tidak sampai ke teman yang akan dituju sehingga bola sering dipotong oleh lawan dan menjadikan alur serangan perpindahan menjadi lambat.

Pelatih juga menginformasikan bahwa latihan tendangan lambung sudah diberikan kepada atlit tetapi belum sepenuhnya bervariasi, Atlit hanya diberikan latihan tendangan lambung secara berpasangan tanpa memberikan latihan untuk memperkuat otot tungkai. Dalam sepakbola, latihan menendang tidak boleh dianggap sebagai suatu hal remeh, dimana pertahanan yang begitu ketat masih bisa ditembus oleh tendangan dari luar daerah kotak pinalti (Batty, 2008:9). Pemahaman dan penguasaan teknik dasar sepakbola yang benar akan membantu seorang pemain untuk dapat melakukan kerjasama kelompok yang baiksi saat bertahan maupun menyerang. Maka suatu tim keseblasan bisa dikatakn baik, tangguh dan kuat adalah keseblasan yang terdiri dari pemain-pemain yang mampu melakukan permainan yang kompak artinya mempunyai kerjasama tim yang baik.

Dalam permainan Sepakbola untuk bisa menghasilkan tendangan melambung jarak jauh lebih tepat bila menggunakan kata-kata bagian dalam, karena akan menghasilkan tendangan bola yang parabola sehingga jarak yang akan di tempuh semakin jauh. Agar tendangan menjadi lambung dan keras dibutuhkan power otot tungkai yang maksimal, oleh karena itu perlu melatih power otot tungkai.

Thera Band, 2006 mengatakan untuk melatih daya ledak otot tungkai dapat menggunakan resistance band exercise. Adapun gerakan yang digunakan adalah standing leg extension dan leg press back. Resistance band exersice juga dapat meningkatkan kemampuan fungsional remaja..

\section{METODE}

Penelitian ini menggunakan metode eksperimen dengan rancangan faktorial $2 \mathrm{x}$. Teknik analisis data menggunakan Analysis of Varian (ANOVA) pada taraf signifikansi ( $\alpha$ ) 0,05. Variabel bebas dalam penelitian ini yaitu metode latihan standing leg extension dan leg back press. Power tungkai tinggi dan rendah sebagai variabel atribut dan variabel terikatnya yaitu tendangan lembunng sepak bola.Populasi dalam penelitian ini adalah atlet U-15 SSB Sriwijaya Asah Soccer Palembang yang berjumlah 33 orang. Teknik pengambilan sampel menggunakan purposive sampel dengan jumlah sampel 28 orang. Variabel dalam penelitian ini terdiri dari satu variabel bebas (latihan reisistance band), satu variabel atribut (power tungkai), serta satu variabel terikat (hasil tendangan lambung).

Uji normalitas data bertujuan untuk memperlihatkan bahwa data berasal dari populasi yang berdistribusi normal. Pengujian normalitas data dalam penelitian ini menggunakan uji kolmogorov-smirnov dengan bantuan program SPSS pada taraf signifikansi $\alpha=0,05$. Uji homogenitas bertujuan untuk memperlihatkan bahwa dua atau lebih kelompok data berasal dari populasi yang memiliki variasi yang sama. Uji homogenitas data dalam penelitian ini adalah uji levene dengan bantuan aplikasi SPSS 16,0 pada taraf signifikansi $(\alpha)=0,05$.

Data penelitian yang diperoleh harus dapat dipertanggung jawabkan, maka pengambilan data dalam penelitian ini melalui tes akhir atau post-test dengan melakukan tes keterampilan tendangan lambung. Sebelum program latihan dilakukan, terlebih dahulu dilakukan tes power tungkai dengan cara melakakuan tes standing broad jump, dengan tujuan untuk mengetahui tingkat power tungkai kategori tinggi dan rendah. Kemudian melaksanakan tes awal atau pre-test dengan cara melakukan tes keterampilan tendangan lambun Bentuk tes yang digunakan untuk mengukur hasil tendangan lambung adalah kicking for distance dari warner test of soccer skill.

Dipublikasikan Oleh :

UPT Publikasi dan Pengelolaan Jurnal

Universitas Islam Kalimantan Muhammad Arsyad Al-Banjari Banjarmasin 


\section{HASIL DAN PEMBAHASAN}

Pengujian hipotesis penelitian dilakukan berdasarkan hasil analisis data dan interaksi analisis varians. Untuk mengetahui perbedaan perlu uji ANOVA, hasil ringkasan ANAVA menunjukkan adanya perbedaan yang

\begin{tabular}{lccccc}
\hline \multicolumn{1}{c}{ Source } & $\begin{array}{c}\text { Type Sum of } \\
\text { Squares }\end{array}$ & Df & Mean Square & $F$ & Sig. \\
& 69,049 & 1 & 69,049 & 44,532 & $000^{\mathrm{a}}$ \\
\hline Metode Latihan & 168,872 & 1 & 168,872 & 106,978 & $000^{\mathrm{a}}$ \\
Power Tungkai & 7,313 & 1 & 7,313 & 4,717 & $040^{\mathrm{a}}$ \\
Metode Latihan*Power & & & & & \\
Tungkai & & & & & \\
& 37,213 & 24 & & & \\
Error & 35133,970 & 28 & & & \\
Total & & & & & \\
\end{tabular}

Hipotesis 1 yang menyatakan ada pengaruh antara metode latihan standing leg extension dan leg back press terhadap hasil tendangan lambung pada atlet Sriwijaya Asah Soccer Palembang yang diuji menggunakan uji anova dan diperoleh Fhitung $=44,532$ dengan nilai signifikansi 0,000. Hasil perhitungan ini dikonsultasikan dengan $\mathrm{F}$ table dk pembilang $=1(\mathrm{~b}-1)$ dan dk penyebut $(\mathrm{kb}(\mathrm{n}-1))$, dengan taraf signifikansi 0,005 diperoleh $\mathrm{F}$ tabel $=3,39$, karena Fhitung $>$ Ftabel atau 44,532 > 3,39 dengan taraf signifikansi 0,000 < 0,05 maka Ha yang berbunyi: "ada pengaruh antara metode latihan standing leg extension dan metode latihan leg back press terhadap peningkatan hasil tendangan lambung sepak boola pada atlet SSB Sriwijaya Asah Soccer Palembang" diterima.

Hipotesis 2 yang menyatakan ada pengaruh metode latihan antara atlet yang memiliki power tungkai tinggi dan atlet yang memiliki power tungkai rendah terhadap peningkatan hasil tendangan lambung sepak bola pada atlet SSB Sriwijaya Asah Soccer U-15 diuji menggunakan uji anava dan diperoleh Fhitung = 106,978 dengan nilai signifikansi 0,000 . Hasil perhitungan ini dikonsultasikan dengan table $\mathrm{F}$ dengan dk pembilang $=1$ (b-1) dan dk penyebut (kb(n-1)), dengan taraf signifikansi 0,005 diperoleh Ftabel = 3,39, karena Fhitung > Ftabel atau 106,978 > 3,39 dengan taraf signifikansi 0,000<0,05 maka Ha yang berbunyi: "ada pengaruh metode latihan antara atlet yang memiliki power tungkai tinggi dan atlet yang memiliki power tungkai rendah terhadap hasil tendangan lambungsepak bola pada atlet SSB Sriwijaya Asah Soccer U-15 Palembang” diterima.

Ada interaksi antara metode latihan dan power tungkai terhadap peningkatan hasil tendangan lambung sepak bola pada atlet SSB Sriwijaya Asah Soccer U-15 Palembang, menggunakan uji anava, Fhitung = 4,717 dengan nilai signifikansi 0,000. Hasil perhitungan ini dikonsultasikan dengan table F dengan pembilang $=1(\mathrm{~b}-1) \mathrm{dan} \mathrm{dk}$ penyebut $(\mathrm{kb}(\mathrm{n}-1)$, dengan taraf signifikansi 0,005 diperoleh 0,005 diperoleh Ftabel = 3,39, karena Fhitung > Ftabel atau 4,717 > 3,39 dengan taraf signifikansi 0,000 <0,005 maka Ha yang berbunyi: "ada interaksi antara metode latihan dan power tungkai terhadap peningkatan hasil tendangan lambung sepak bola pada atlet SSB Sriwijaya Asah Soccer U-15 Palembang” diterima.

Standing leg extension merupakan latihan otot bagian paha depan. Standing leg extension ini melatih otot quadrisep (Brian J Sharkey, 2003:219). Kedua latihan ini sama-sama melatih kekuatan otot tungkai terutama kekuatan otot paha bagian depan maupun belakang. Metode latihan standing leg extension menekankan pada kekuatan otot quadrisep untuk mencapai kekuatan. Latihan standing leg extension gerakannya sama dengan melakukan menendang bola yaitu dari posisi ditekuk dilanjutkan dengan kaki diluruskan pada saat menendang bola, sebaliknya latihan leg back press yang menekankan pada kekuatan otot hamstring dan gerakan leg back

Dipublikasikan Oleh :

UPT Publikasi dan Pengelolaan Jurnal

Universitas Islam Kalimantan Muhammad Arsyad Al-Banjari Banjarmasin 
press kebalikan dari gerakan menendang. Sehaingga latihan standing leg extension lebih baik dilakukan dari pada latihan leg back press untuk meningkatkan hasil tendangan lambung.

Dalam sepak bola agar tendangan menjadi lambung dan keras tentu membutuhkan power tungkai yang maksimal (Weineck, 2000). Power adalah kekuatan otot untuk mengerahkan kekuatan maksimal dalam waktu yang sangat cepat. Sedangkan (Kraemer, 2003) power adalah hasil usaha dalam satuan unit waktu yang disebabkan ketika kontrkasi otot memindahkan benda pada ruang atau jarak tertentu. Sedangkan yang dimaksud power tungkai dalam penelitian ini adalah kemampuan seseorang dalam menggunakan sekelompok otot tungkai untuk menghasilkan kekuatan yang maksimalpada waktu menendang dengan waktu sependek-pendeknya untuk menghasilkan suatu gerakan yang utuh dengan kekuatan yang maksimal (Weineck, 2000). Dari beberapa literatur diatas maka penulis menyimpulkan untuk menghasilkan tendangan lambung yang jauh diperlukan power tungkai yang tinggi.

Terdapat adanya interaksi antara metode latihan standing leg extension dan leg back press, power tungkai terhadap hasil tendangan lambung disebabkan karena bentuk latihan keduanya memilki kesamaan yang sama-sama menggunakan alat. Sama dengan tujuan standing leg extension dan leg back press ini juga digunakan untuk otot tungkai diperlukan dalam melakukan rangkaian gerakan saat menendang bola. Otot tungkai digunakan sebagai ayunan dalam melakukan rangkaian gerakan menendang bola, yaitu datri gerakan awal hingga gerakan akhir.

\section{PENUTUP}

Simpulan

Berdasarkan hasil analisis dan pembahasan tersebut di atas, maka dapat disimpulkan sebagai berikut: (1) Ada pengaruh antara metode latihan standing leg extension dan leg back press terhadap peningkatan hasil tendangan lambung sepak bola pada atlet SSB Sriwijaya Asah Soccer Palembang. Metode latihan standing leg extension mempunyai peranan yang lebih baik dalam meningkatkan hasil tendangan lambung atlet SSB Sriwijaya Asah Soccer Palembang dibandingkan dengan metode latihan leg back press. (2) Ada pengaruh antara atlet yang memilki power tungkai tinggi dan yang memiliki power tungkai rendah terhadap hasil tendangan lambung sepak bola pada atlet SSB Sriwijaya Asah Soccer Palembang. Hasil tendangan lambung sepak bola atlet juga dipengaruhi oleh tingkat power tungkai. Atlet yang memilki power tungkai tinggi mempunyai hasil tendangan lambung sepak bola lebih baik dibandingkan dengan atlet yang memiliki power tungkai rendah. (3) Ada interaksi antara metode latihan resistance band dan power tungkai terhadap peningkatan hasil tendangan lambung sepak bola pada atlet SSB Sriwijaya Asah Soccer Palembang disebabkan karena bentuk latihan keduanya memilki kesamaan yang sama-sama menggunakan alat. Sama dengan tujuan standing leg extension dan leg back press ini juga digunakan untuk otot tungkai diperlukan dalam melakukan rangkaian gerakan saat menendang bola. Otot tungkai digunakan sebagai ayunan dalam melakukan rangkaian gerakan menendang bola, yaitu datri gerakan awal hingga gerakan akhir.

Saran

Peneliti menyarankan kepada pelatih SSB Sriwijaya Asah Soccer Palembang, khususnya untuk meningkatkan hasil tendangan lambung atlet secara optimal sebaiknya pelatih menggunakan atau menerapkan metode latihan resistance band dengan memperhatikan tingkat power tungkai atlet.

Hasil dari penelitian ini diharapkan dapat menambah wawasan para atlet mengenai latihan yang tepat mengenai peningkatan hasil tendangan. Peneliti juga mengharapkan para atlet untuk giat berlatih guna menghasilkan prestasi yang optimal,

Peneltitan ini dapat menambah wawasan dan pengalaman bagi peneliti dalam menerapkan pengetahuan yang diperoleh dibangku kuliah khususnya masalah yang dihadapi di dunia olahraga..

\section{REFERENSI}

Brian J Sharkey (2003). Kebugaran dan kesehatan. Jakarta : PT. Raja Grafindo Persada

Chandra, Sodikin dan Sanoesi, Esnoe Achmad. 2010. PendidikanJasmani Olahraga Dan Kesehatan. Surabaya: CV. Karya Utama

Jurgen weineck, Optimales Training, (Deutshland Sputa Verlag GmbH \& Co. KG, Balingen)

Dipublikasikan Oleh :

UPT Publikasi dan Pengelolaan Jurnal

Universitas Islam Kalimantan Muhammad Arsyad Al-Banjari Banjarmasin 
Kraemer, W. et al. (2003). Physiological Changes With Periodized Resistance Training In Women Tennis Players. Journal Of Medicine \& Science In Sports \& Exercise. 35,(1),157-168.

Mochtar Remmy, 1992 Olahraga Pilihan Sepakbola. Depdikbud. Dirjen Dikti Proyek Pembinaan Tenaga Pendidikan

Sucipto, dkk.. 2001. Sepak Bola. Depdiknas Direktorat Jenderal Pendidikan Dasar dan Menengah Bagian Proyek Penataran Guru SLTP Setara D-III.

Sukatamsi, 1984 Teknik Dasar Bermain Sepakbola

Thera Band, Resistance Band \& Tubing Instruction Manual, Volume 4 